\title{
Variation in oleoresin yield and anatomical traits among Sindora glabra populations in Hainan, China
}

\author{
Niu $\mathrm{Yu}^{1,2}$ - Qiongqiong $\mathrm{Li}^{1,2}$ • Jinchang Yang ${ }^{1,2} \cdot$ Guangtian $\mathrm{Yin}^{1,2} \cdot$ Rongsheng $\mathrm{Li}^{1,2} \cdot$ Wentao Zou ${ }^{1,2}$
}

Received: 19 November 2019 / Accepted: 6 June 2020 / Published online: 17 June 2020

(c) The Author(s) 2020

Key message Geography and tree diameter were the major factors in determining oleoresin yield in Sindora glabra. The tangential diameter and area of secretory canals are reliable indicators of the oleoresin amount.

Abstract Sindora glabra is a native tropical plant of China that exudes copious amounts of oleoresin from wounds on the stem. Elucidation of the mechanism affecting the oleoresin yield is of particular importance for development and selection of superior germplasm. In this study, the variation in oleoresin yield and anatomical traits of the stem of S. glabra were investigated in four main natural populations in Hainan. The results showed that annual oleoresin yield varied considerably among populations. The oleoresin yield exhibited an increasing trend with the increment of tree stem diameter until the diameter was over $80 \mathrm{~cm}$. Moreover, oleoresin production in the wet season was higher than in dry season. The analysis of oleoresin chemical composition indicated that the four populations belong to the same chemotype despite the amount of four types of sesquiterpenes varying greatly among areas. Anatomical analysis revealed that quantitative traits of secretory canals including tangential diameter, area, density and frequency were significantly different among populations and tree diameters. Furthermore, the tangential diameter and area of secretory canals were positively correlated with oleoresin yield. These results suggested that the tangential diameter and area of secretory canals are reliable indicators of the oleoresin amount and can be used for selection purposes in S. glabra.

Keywords Oleoresin $\cdot$ Sesquiterpene $\cdot$ Secretory canal $\cdot$ Sindora glabra

\section{Introduction}

Terpenes are one of the largest specialized metabolites in plants for self-protection (Lombardero et al. 2000; Bolutari et al. 2013; Tolera et al. 2013). Terpenes not only play important roles in ecosystems, but also are widely used in pharmaceuticals and fragrance industries. Most terpenes are extracted from plants due to their diversity and complexity which make it difficult to synthesize them. Therefore, it is

Electronic supplementary material The online version of this article (https://doi.org/10.1007/s00468-020-02000-y) contains supplementary material, which is available to authorized users.

Jinchang Yang

fjyjc@126.com

1 Key Laboratory of State Forestry Administration on Tropical Forestry Research, Research Institute of Tropical Forestry, Chinese Academy of Forestry, Guangzhou 510520, China

2 Research Institute of Tropical Forestry, Chinese Academy of Forestry, Number 682, Guang Shan Yi Road, Longdong District, Guangzhou 510520, China becoming increasingly important to explore new plant species with abundant terpenes in addition to enhancing terpene amount in the existing plants.

Oleoresin is a concentrated extract composed of essential oil which contains, inter alia, terpenes. Tropical regions are the main sources of oleoresin production. Two-thirds of the plants that exude oleoresin are from the tropical angiosperms (Langenheim 1990). Sindora glabra Merr. ex de Wit (Fabaceae) is a tropical tree with copious amounts of terpenes. Its main natural distribution is confined to Ledong, Diaoluoshan, Wuzhishan and Bawangling areas on Hainan Island, China. S. glabra known as the diesel tree by local people exudes yellowish or amber liquid oil when wounded or tapped. The oleoresin production and composition of $S$. glabra are very similar to the oleoresin of Copaifera species, which has been used as a traditional medicine in Neotropical regions for thousands of years and has attracted a lot of studies (Cascon et al. 2000; Trindade et al. 2018). Oleoresin production is affected by both biotic and abiotic factors. Oleoresin yield in the wet season was found to be higher than that in the dry season (Zoghbi et al. 2007). No oleoresin was 
secreted in Copaifera tree with a trunk diameter smaller than $45 \mathrm{~cm}$ (Plowden 2003; Medeiros et al. 2008). Furthermore, most of the trees which exuded oleoresin were attacked by termites, while trees without termite infestations did not produce oleoresin.

Secretory canals and cavities are widely distributed in leaf, stem, fruit and root tissues of vascular plants (Fahn 1979). The secretory spaces can store compounds of gum, essential oil and oleoresin. They exist in different developmental stages of plants and their genesis and structural traits are widely influenced by different ecological parameters. Light intensity and temperature significantly influenced the cellular features of secretory canals in Copaifera langsdorffii seedlings. Seedlings grown at $25^{\circ} \mathrm{C}$ had higher density of secretory canals than those grown at 15 and $35{ }^{\circ} \mathrm{C}$ (Rodrigues et al. 2014). The anatomical features of secretory canals such as diameter and density of secretory canals may serve as reliable indicators for oleoresin production (Rosner and Hannrup 2004). In Citrus medica, the accumulation of essential oil coincided with changes in the diameter of the lumen of secretory cavities (Liang et al. 2006). In Boswellia papyrifera, individuals with the same breast height diameter varied in diameter of secretory canals. The variation in qualitative and quantitative characteristics of secretory canals has also been reported for populations of the same species in Erythroxylum ovalifolium (Mantuano et al. 2006). Nevertheless, the studies on the secretory canals in Copaifera were mostly conducted in seedlings, young trees and vegetative organs such branches, secondary roots and leaves. There were no reports about the study of secretory canals from the main stem part, which contains the majority of oleoresin. Dünisch and Baas (2006) found great variation in the presence and frequency of traumatic axial canals in Meliaceae. Apart from insect or mechanical damage to shoot apices and the cambium, growth stresses in fast growing plantation trees also induced the formation of canals.

In this study, the effects of geographical origin, tree diameter and season on the oleoresin yield and chemical composition were investigated in S. glabra. Resin secretory structures were examined, and the relationship between secretory canal features and accumulation of oleoresin yield was determined. The results could provide useful information for germplasm exploitation and evaluation, and lay a foundation for future efforts to enhance the oleoresin yield in S. glabra.

\section{Materials and methods}

\section{Plant material}

All plant materials used for oleoresin and anatomical characteristics analysis were collected from four main natural populations on Hainan Island, China, viz. Jiangfengling (JFL), Diaoluoshan (DLS), Bawangling (BWL) and Wuzhishan (WZS) (Fig. 1). Diameter at breast height (DBH) was measured and the individuals from different distribution areas were classified into five classes according to their DBH value. The environmental condition and sampling information are given in Table 1.

An auger $5 \mathrm{~mm}$ in diameter was used to drill hole on the main stem at $30 \mathrm{~cm}$ above the ground. The depth of hole was slightly greater than a half of the stem diameter. A steel pipe was inserted into the hole and connected with an aluminum bottle for oleoresin collection. Oleoresin was harvested and quantified in weight monthly over a period of 2 years from January 2014 to December 2015 and stored at room temperature until further analysis. In Hainan Island, the dry season was defined from April to September and the wet season was defined from October to March according to the amount of precipitation. For the comparison of oleoresin amount between different periods of the year, the oleoresin samples collected monthly were quantified and summed as oleoresin yield during the period for each tree. For anatomical studies, a wood increment core was taken from each individual tree.

\section{GC-MS analysis}

The oleoresin samples collected monthly were combined as one sample for each tree and only the oleoresin collected in the first year was used for compound analysis. An aliquot of $0.1 \mathrm{~mL}$ of oleoresin was added with dichloromethane to a total volume of $100 \mathrm{~mL}$ and allowed to stand for $2 \mathrm{~h}$. Then the solution was filtered and $1 \mu \mathrm{L}$ of sample was injected into GC-MS (Agilent 6890) system for separation and identification of the terpene compounds. The DB-5MS column was $30 \mathrm{~m} \times 0.25 \mathrm{~mm} \times 0.25 \mu \mathrm{m}$. The injection temperature was $250{ }^{\circ} \mathrm{C}$ with a $60: 1$ split ratio. The program was $70^{\circ} \mathrm{C}$ for 2 min and then increased at the rate of $8{ }^{\circ} \mathrm{C} / \mathrm{min}$ to $280{ }^{\circ} \mathrm{C}$ and held for $4 \mathrm{~min}$. The compounds were identified by comparison of the mass spectra with NIST14 standard library. Relative percentage of the identified compounds were computed based on the peak area.

\section{Anatomical analysis}

The wood cores were cut into four regions at the distance of $0 / 3,1 / 3,2 / 3$ and $3 / 3$ away from the pith, respectively. Each region was $20 \mathrm{~mm}$ in length and $5 \mathrm{~mm}$ in diameter. The samples were first boiled in water for $3 \mathrm{~h}$ and then softened in glycerol and 70\% ethanol (1:1) for 2 weeks. Then $15-\mu \mathrm{m}$-thick cross sections were obtained by means of a Leica RM2255 rotary microtome. The sections were 
Fig. 1 Distribution areas of $S$. glabra in China. JFL Jiangfengling, $D L S$ Diaoluoshan, $B W L$ Bawangling, WZS Wuzhishan

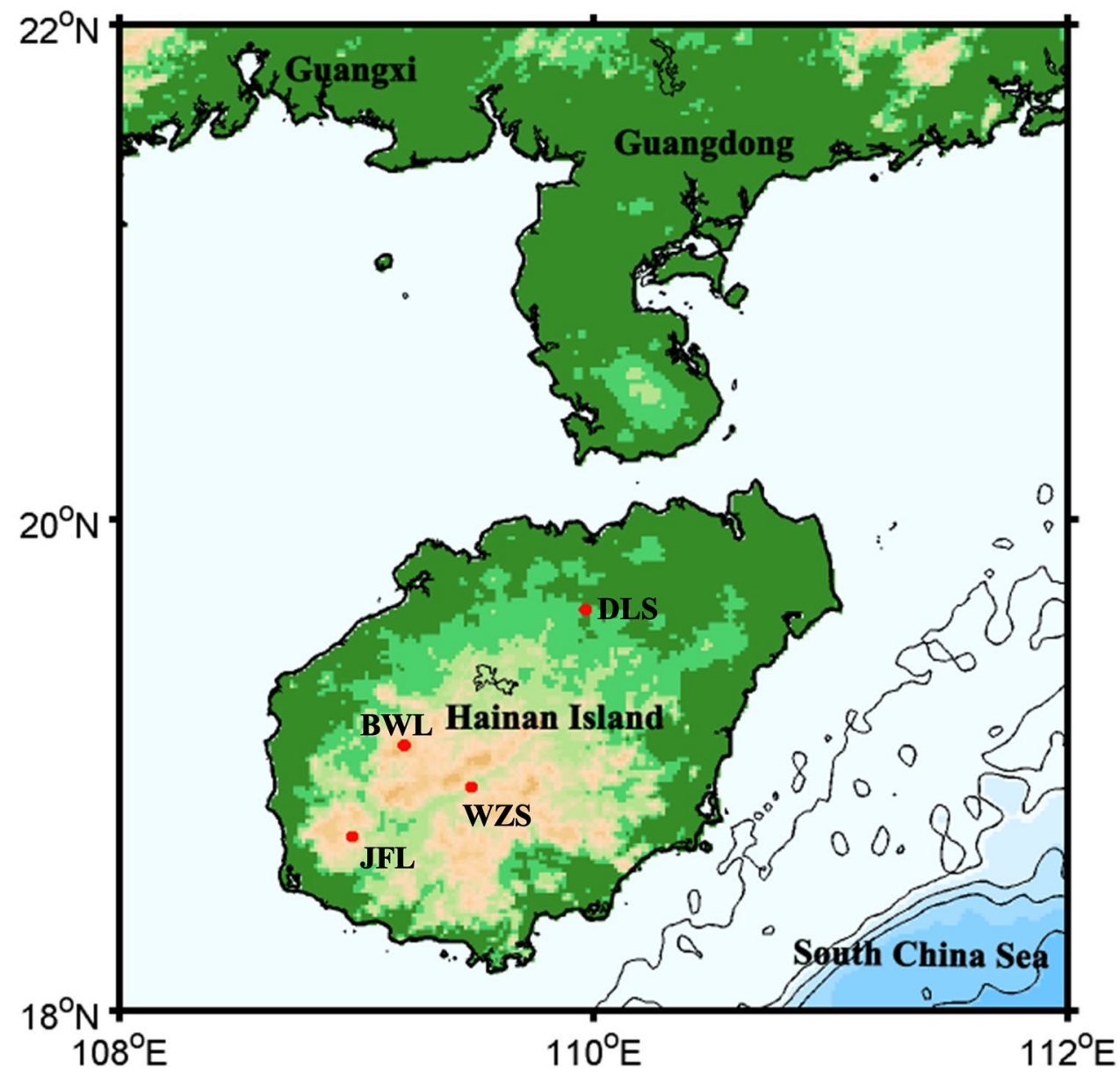

Table 1 Sampling site coordinates and number of collected samples

\begin{tabular}{|c|c|c|c|c|c|c|c|c|c|c|c|}
\hline \multirow[t]{2}{*}{ Population } & \multirow{2}{*}{$\begin{array}{l}\text { Longitude } \\
\text { (E) }\end{array}$} & \multirow{2}{*}{$\begin{array}{l}\text { Latitude } \\
\text { (N) }\end{array}$} & \multirow{2}{*}{$\begin{array}{l}\text { Altitude } \\
(\mathrm{m})\end{array}$} & \multirow{2}{*}{$\begin{array}{l}\text { Temperature } \\
\left({ }^{\circ} \mathrm{C}\right)\end{array}$} & \multirow{2}{*}{$\begin{array}{l}\text { Precipitation } \\
(\mathrm{mm})\end{array}$} & \multicolumn{5}{|c|}{$\mathrm{DBH}(\mathrm{cm})$} & \multirow[t]{2}{*}{ Total } \\
\hline & & & & & & $20-35$ & $36-50$ & $51-65$ & $66-80$ & $>80$ & \\
\hline JFL & $108^{\circ} 57^{\prime}$ & $18^{\circ} 44^{\prime}$ & 360 & 25.3 & 2030 & $6(3)$ & $12(4)$ & $16(5)$ & $6(5)$ & 0 & 40 (17) \\
\hline DLS & $109^{\circ} 56^{\prime}$ & $19^{\circ} 39^{\prime}$ & 192 & 24.9 & 2540 & $3(3)$ & $8(3)$ & $4(4)$ & $7(4)$ & 4 & $26(14)$ \\
\hline BWL & $109^{\circ} 10^{\prime}$ & $19^{\circ} 06^{\prime}$ & 507 & 24.6 & 1676 & $4(4)$ & $5(5)$ & $15(5)$ & $4(3)$ & 2 & $30(17)$ \\
\hline WZS & $109^{\circ} 27^{\prime}$ & $18^{\circ} 56^{\prime}$ & 435 & 22.5 & 2420 & $11(4)$ & $10(3)$ & $5(4)$ & 0 & 0 & $26(11)$ \\
\hline
\end{tabular}

JFL, DLS, BWL and WZS represent Jianfengling, Diaoluoshan, Bawangling, Wuzhishan in Hainan Province, respectively. The number in brackets indicate sample number for anatomical analysis

stained with $1 \%$ carmine and $1 \%$ astra blue in ethanol solution, and dehydrated in the series of graded ethanol. Finally, sections were photographed with a light microscope Olympus BH-2 equipped with UC501S camera. The ImageJ software (National Institutes of Health, USA) was used for measurement of secretory canals traits.

More specifically, the tangential diameter (SCTD) $(\mu \mathrm{m})$ and the area of secretory canals (SCA) $\left(\mu \mathrm{m}^{2}\right)$ were calculated as average of at least ten mature secretory canals. The density of secretory canals (SCD) was calculated as the number of secretory canals per $\mathrm{mm}^{2}$ (number $\left./ \mathrm{mm}^{2}\right)$. The total area of secretory canals (SCTA) was calculated as area multiplied by density $\left(\mu \mathrm{m}^{2} / \mathrm{mm}^{2}\right)$. The frequency of secretory canals (SCF) was calculated as the number of secretory canals per $\mathrm{mm}$ (number/mm). The total tangential diameter of secretory canals (SCTTD) was calculated as tangential diameter multiplied by frequency $(\mu \mathrm{m} / \mathrm{mm})$. The frequency of marginal bands (MBF) was calculated as the number of marginal bands per $\mathrm{mm}$ (number/mm). The growth rate (mm/years) 
was calculated as the DBH (mm) divided by predicted age (total number of annual rings visually detected).

To elucidate the relationship between oleoresin yield and secretory canal traits, all individuals in each population were classified into three grades HY (high yield), MY (medium yield) and LY (low yield). Individuals with oleoresin yield larger than the average of all individuals were defined as HY, while those with oleoresin yield less than the half of the average of all individuals were LY, and those between were MY. To investigate the effects of growth rate on traits of secretory canals, a correlation analysis between them was performed.

\section{Statistical analysis}

One-way analysis of variance (ANOVA) was performed with SPSS 20.0 software. Duncan's multiple range test was used to determine the significant differences including geography and DBH as factors. The data about annual oleoresin yield among four populations were inconsistent with normal distribution, and then nonparametric tests (Kruskal-Wallis) were used for comparison.

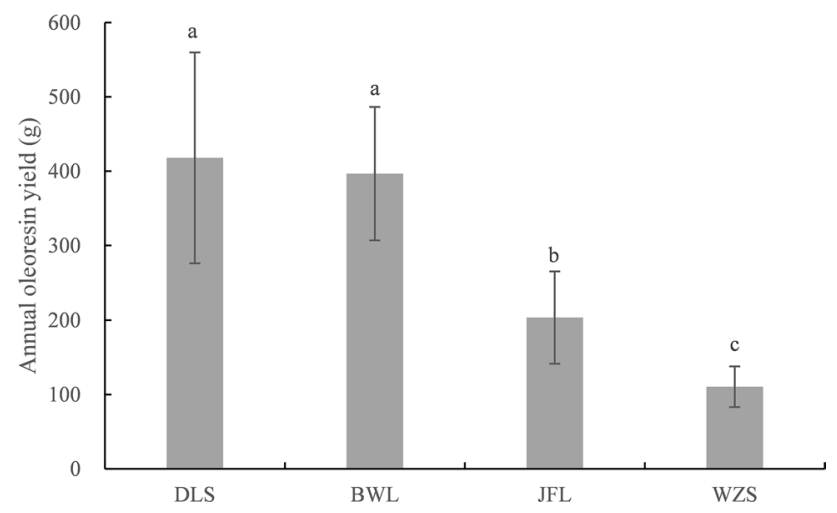

Fig. 2 Annual oleoresin yield of S. glabra among four populations. Data are mean values \pm standard errors. One-way ANOVA was used for statistical analysis. The different letters indicate significant differences $(p<0.05)$

\section{Results}

\section{Variation in oleoresin yield}

Annual oleoresin amount in S. glabra varied considerably among four populations. Populations from DLS and BWL areas exuded an average of $417.9 \pm 141.8 \mathrm{~g}$ and $396.6 \pm 89.8$ g oleoresin per year (Fig. 2), respectively, which were about twice the amount from JFL $(203.5 \pm 62.1$ g) and four times than those from WZS $(110.5 \pm 27.4 \mathrm{~g})$ areas. Annual oleoresin yield from DLS and BWL populations was significantly different to those in JFL and WZS populations $(p<0.05)$.

To evaluate the effect of DBH on oleoresin yield, the individuals from different distribution areas were classified into five classes according to their DBH value (Table 1). The highest amount of oleoresin production was found among individuals with 66-80 $\mathrm{cm} \mathrm{DBH}$, and the lowest oleoresin yield was with $20-35 \mathrm{~cm}$ DBH (Table 2). The annual oleoresin yield of individuals from DLS and BWL areas increased with increasing DBH and began to decrease when DBH was $>80 \mathrm{~cm}$, while oleoresin yield of individuals from JFL and WZS areas increased with increasing DBH.

The effect of season on oleoresin yield was examined in two continuous years. In Hainan Island, the total precipitation in wet season was nearly ten times than that in dry season (Fig. 3a). It was noteworthy that the oleoresin yield in the rainy season in JFL and DLS in the first year was significantly higher than in the dry season (Fig. 3b), while the oleoresin yield in the dry season in DLS population in the second year was significantly higher than in the rainy season. Moreover, the yields of four populations in the first year were always significantly higher $(p<0.05)$ than in the second year in both seasons. These indicated that season could be an important factor in affecting oleoresin production in S. glabra.
Table 2 Variation of annual oleoresin yield among individuals with different DBH

\begin{tabular}{lcllr}
\hline DBH $(\mathrm{cm})$ & JFL $(\mathrm{g})$ & DLS $(\mathrm{g})$ & BWL $(\mathrm{g})$ & \multicolumn{1}{c}{ WZS $(\mathrm{g})$} \\
\hline $20-35$ & $77.5 \pm 33.1 \mathrm{~b}$ & $231.5 \pm 67.6 \mathrm{ab}$ & $128.1 \pm 68.4 \mathrm{~b}$ & $44.7 \pm 16.8 \mathrm{~b}$ \\
$36-50$ & $78.1 \pm 43.2 \mathrm{~b}$ & $150.4 \pm 62.6 \mathrm{~b}$ & $279.5 \pm 112.5 \mathrm{~b}$ & $141.1 \pm 47.9 \mathrm{a}$ \\
$51-65$ & $166.5 \pm 35.6 \mathrm{ab}$ & $294.8 \pm 154 . \mathrm{ab}$ & $380.1 \pm 113.4 \mathrm{~b}$ & $194.4 \pm 89.2 \mathrm{a}$ \\
$66-80$ & $679.1 \pm 354.8 \mathrm{a}$ & $878.3 \pm 492.7 \mathrm{a}$ & $907.2 \pm 464.2 \mathrm{a}$ & \\
$>80$ & & $410.2 \pm 101.7 \mathrm{ab}$ & $328.5 \pm 40.4 \mathrm{~b}$ & \\
\hline
\end{tabular}

Data are means \pm standard error. The different letters after values in the same column indicate significant differences $(p<0.05)$ 
(a)

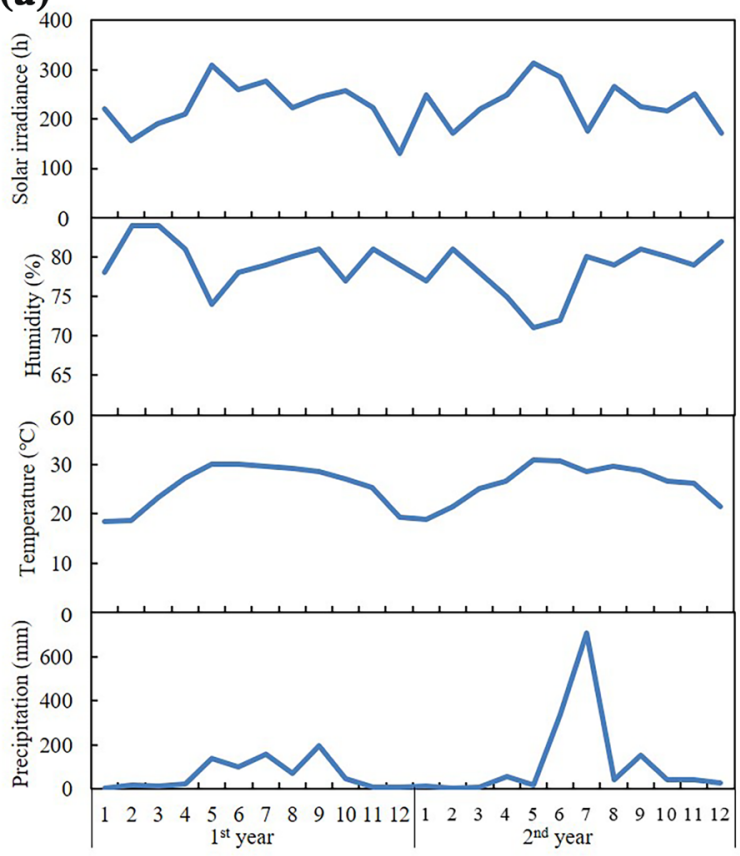

Fig. 3 Meteorological data and seasonal variation of oleoresin yield in S. glabra. a Graph of solar radiation, relative humidity, temperature and precipitation during two continuous sampling years in meteorological station Dongfang 59838 (Longitude $108^{\circ}$ 62', Latitude $\left.19^{\circ} 10^{\prime}\right)$. The meteorological data are obtained from National Mete-

\section{Variation of oleoresin composition}

The results showed that all individuals contained 18 types of sesquiterpenes and resin acids (Fig. 4), among which sesquiterpenes accounted for about $86.34 \%$ of total identified components (Table 3). The qualitative profile of oleoresin in four populations did not differ greatly. Among the identified components, $\alpha$-copaene was the most abundant $(36.52 \% \pm$ $8.9 \%)$, followed by $\beta$-caryophyllene $(20.73 \% \pm 6.9 \%)$, and resin acids $(13.66 \% \pm 6.1 \%)$. The amount of aromadendrene, humulene, germacrene $\mathrm{D}$ and amorphene were in the range of $1-5 \%$, while other components including muurolene, cadinene and caryophyllene oxide were less than $1 \%$. The amount of oleoresin component from trees in different distribution areas exhibited a certain degree of variation. The major compounds $\alpha$-copaene and $\beta$-caryophyllene, and minor components $\beta$-copaene, $\alpha$-humulene, $\gamma$-humulene and $\alpha$-amorphene showed significant difference among different populations with various DBH range. The amount of $\alpha$-copaene was the highest in BWL population with $66-80 \mathrm{~cm} \mathrm{DBH}(49.0 \% \pm$ $12.1 \%$ ) and the lowest in DLS population with $20-35 \mathrm{~cm}$ DBH $(23.6 \% \pm 3.7 \%)$, while $\beta$-copaene was the highest in BWL population with $36-50 \mathrm{~cm}$ DBH $(11.1 \pm 0.8 \%)$ and the lowest in JFL population with $66-80 \mathrm{~cm} \mathrm{DBH}(1.9 \pm 1.7 \%)$. Compound $\beta$-caryophyllene was the most abundant in DLS (b)

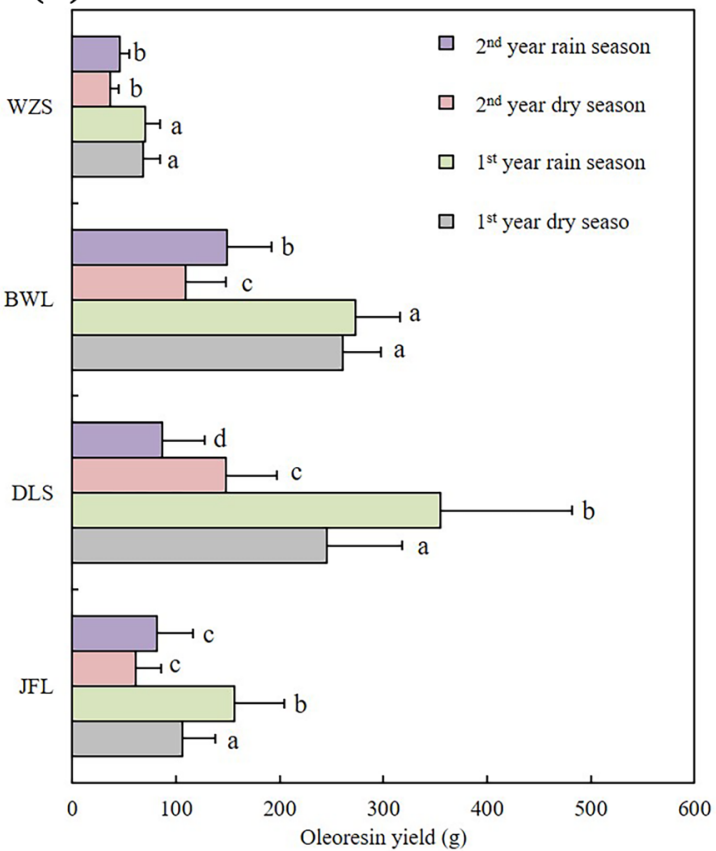

orological Information Center. b Variation of oleoresin yield between dry and rainy season. Data are mean values \pm standard errors. Oneway ANOVA was used for statistical analysis. The different letters in the same population indicate significant differences $(p<0.05)$

population with $60-80 \mathrm{~cm} \mathrm{DBH}(32.3 \% \pm 13.2 \%)$ and the least abundant in BWL population with $36-50 \mathrm{~cm}$ DBH $(10.5 \% \pm$ $4.8 \%)$. The amount of $\alpha$-humulene varied strongly, ranging from $1.8 \pm 1.3 \%$ in the BWL population with $20-35 \mathrm{~cm} \mathrm{DBH}$ to $4.4 \pm 1.3 \%$ in the DLS population with $66-80 \mathrm{~cm} \mathrm{DBH}$, and $\gamma$-humulene varied from $1.2 \pm 0.3 \%$ in the DLS population with $20-35 \mathrm{~cm}$ DBH to $2.5 \pm 0.8 \%$ in the DLS population with $51-65 \mathrm{~cm}$ DBH. The amount of $\alpha$-amorphene was the highest in the BWL population with 51-65 $\mathrm{cm} \mathrm{DBH}(7.2 \pm 0.9 \%)$, and the lowest in the WZS population with $20-35 \mathrm{~cm}$ DBH $(1.0 \pm 0.3 \%)$. The amount of other components including $\beta$-copaene, aromadendrene, germacrene $\mathrm{D}, \alpha$-muurolene, cadinene and caryophyllene oxide was similar among the four populations. Correlation analysis revealed that $\mathrm{DBH}$ was positively correlated with the amount of $\alpha$-copaene $(r=0.464$, $p=0.007)$ and $\gamma$-humulene $(r=0.613, p=0.0002)$, and DBH was negatively correlated with resin acids $(r=-0.466$, $p=0.007)$.

\section{Variation of secretory canal traits}

The anatomy of intercellular canals in the outer sapwood and in the heartwood of S. glabra is reported in Fig. 5. The secretory canals in the secondary xylem of $S$. glabra trunk were 


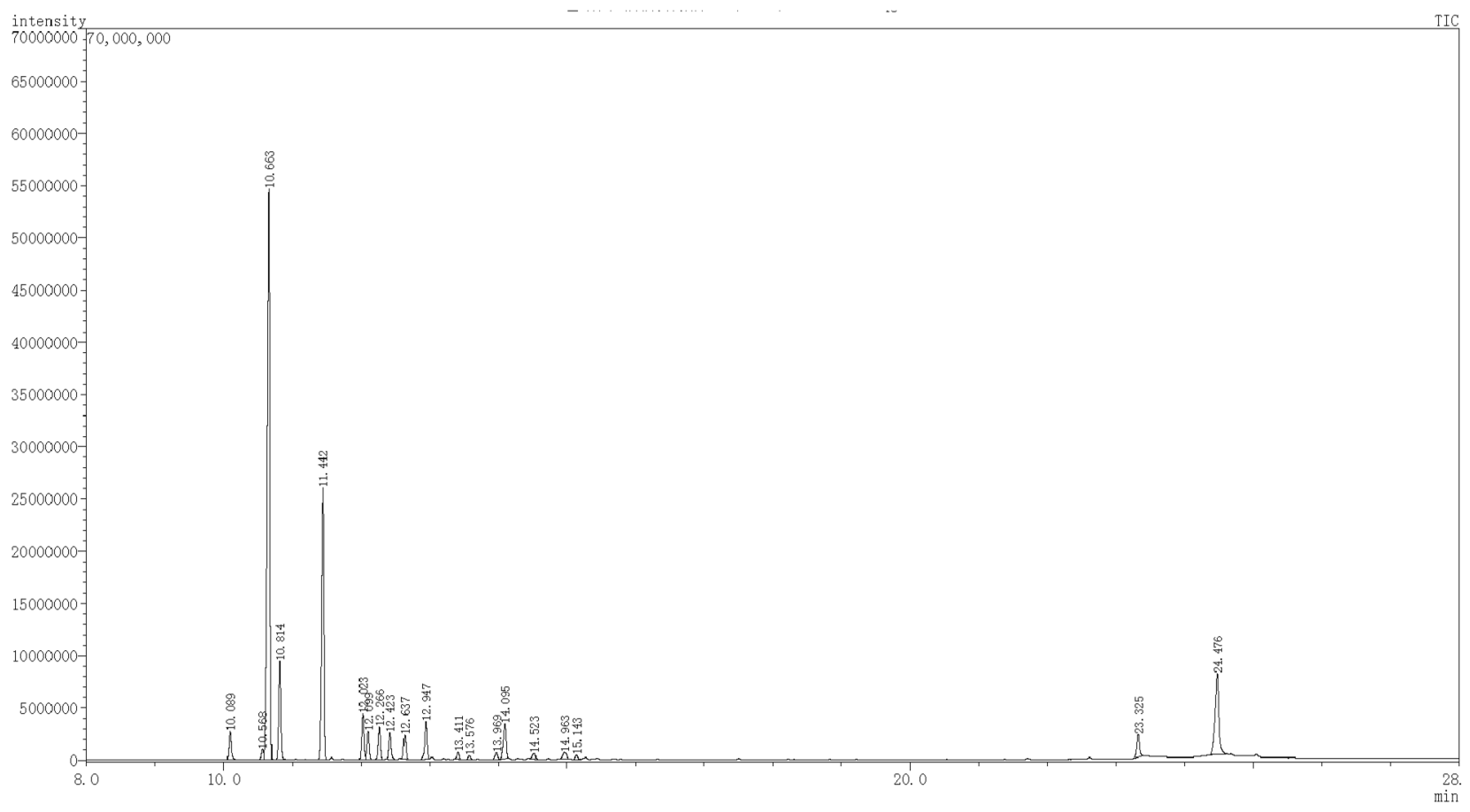

Fig. 4 GC-MS chromatogram of oleoresin from S. glabra stem

present as axial canals distributed along the marginal parenchyma bands and arranged in tangential direction. They were originated from the initial parenchyma cells in the cambial zone derived from fusiform initials or ray initials. The secretory canals were formed by schizolysigenesis and the canals probably form an anastomosing network, with canal fusion, and perhaps even canal tapering and ending.

The ANOVA results revealed that all seven quantitative indicators except the area of secretory canals showed significant differences among populations (Table 4). The tangential diameter of secretory canals in the trunk from JFL and DLS samples was significantly larger than that from WZS. The total area of secretory canals per $\mathrm{mm}^{2}$ in JFL population was $3806 \pm 414 \mu \mathrm{m}^{2} / \mathrm{mm}^{2}$, which was significantly larger than those in DLS and BWL. Moreover, the density of secretory canals and frequency of marginal bands in JFL and WZS were higher than those in DLS and BWL. The individuals from JFL area showed the highest density of secretory canals $\left(2.7 \pm 0.19 / \mathrm{mm}^{2}\right)$ and frequency of marginal bands $(0.48 \pm 0.034 / \mathrm{mm})$, while individuals from WZS area exhibited the highest frequency of secretory canals $(6.1 \pm 0.18 /$ $\mathrm{mm})$.

Furthermore, the secretory canal traits were examined and compared among individuals with different DBH value. In total, the tangential diameter, area and total tangential diameter of secretory canals showed significant difference among different DBH classes (Table 5). The tangential diameter and density of secretory canals, and frequency of marginal bands exhibited an increasing trend with the increment of DBH, which reached maximum at $66-80 \mathrm{~cm} \mathrm{DBH}$, and the highest value were $64 \pm 1.0 \mu \mathrm{m}, 2.5 \pm 0.24 / \mathrm{mm}^{2}$ and $0.44 \pm 0.044 / \mathrm{mm}$, respectively. The other indicators except the frequency of secretory canals all showed the highest value at $66-80 \mathrm{~cm}$ DBH.

All six indicators of secretory canals except the frequency were larger in 100-200 years of trees than those in 40-100 years of trees (Table 6). Moreover, the tangential diameter, density, total area and frequency of marginal bands showed significant difference among different ages of trees.

\section{Correlation analysis}

Secretory canal traits were compared among different grades in each population (Fig. 6). The tangential diameter of secretory canals in $\mathrm{HY}$ were significantly larger than MY and LY in JFL, DLS and BWL populations, while area, total area and total tangential diameter of secretory canals in HY were also larger than MY and LY in BWL population. Other indicators did not show significant difference among HY, MY and LY individuals.

Correlation analysis of the quantitative traits of secretory canals in four populations was performed (Supplemental Tables 1-4). The results revealed that frequency of secretory canals was positively correlated with total tangential diameter in all four populations. Furthermore, 


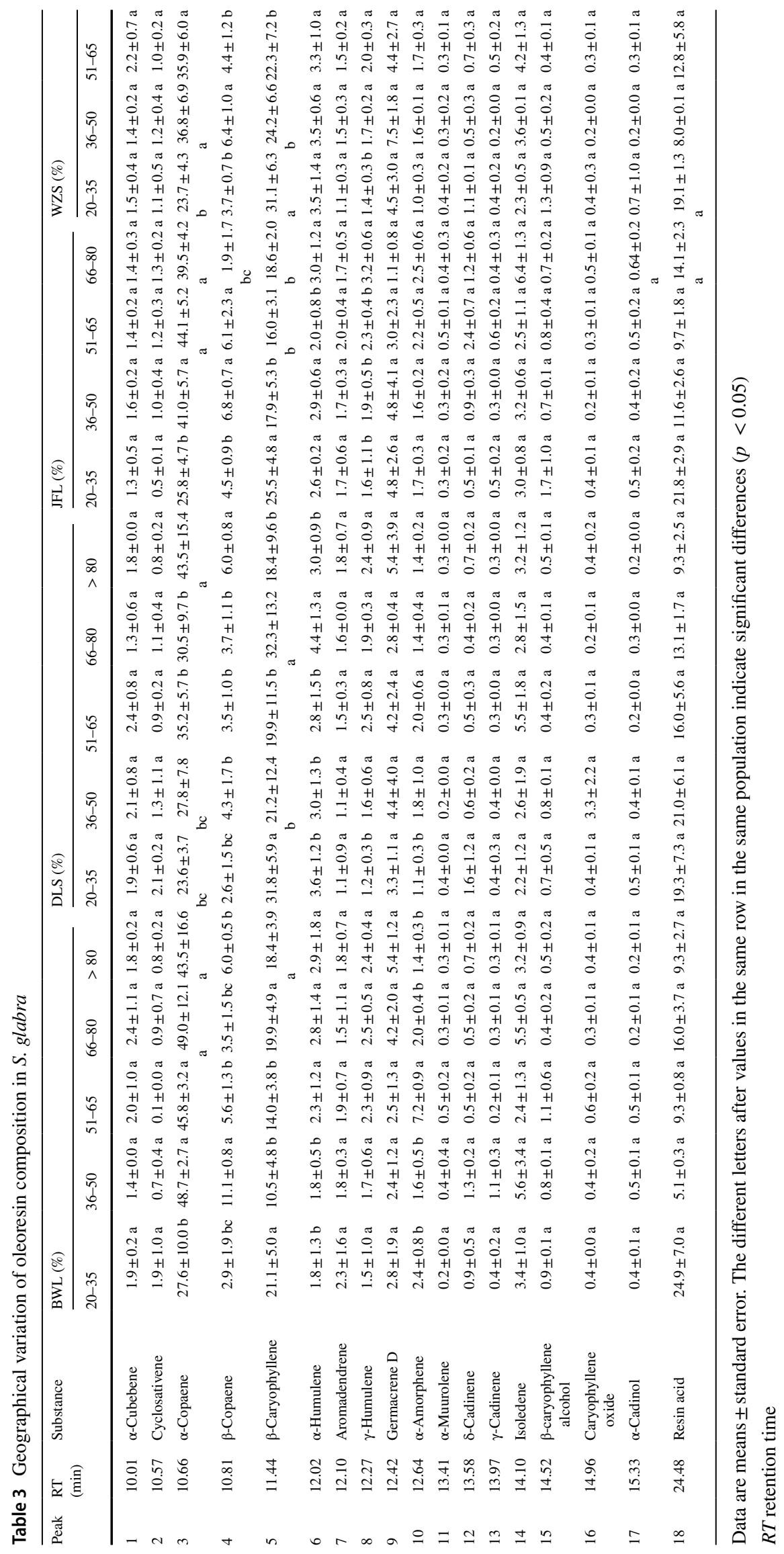



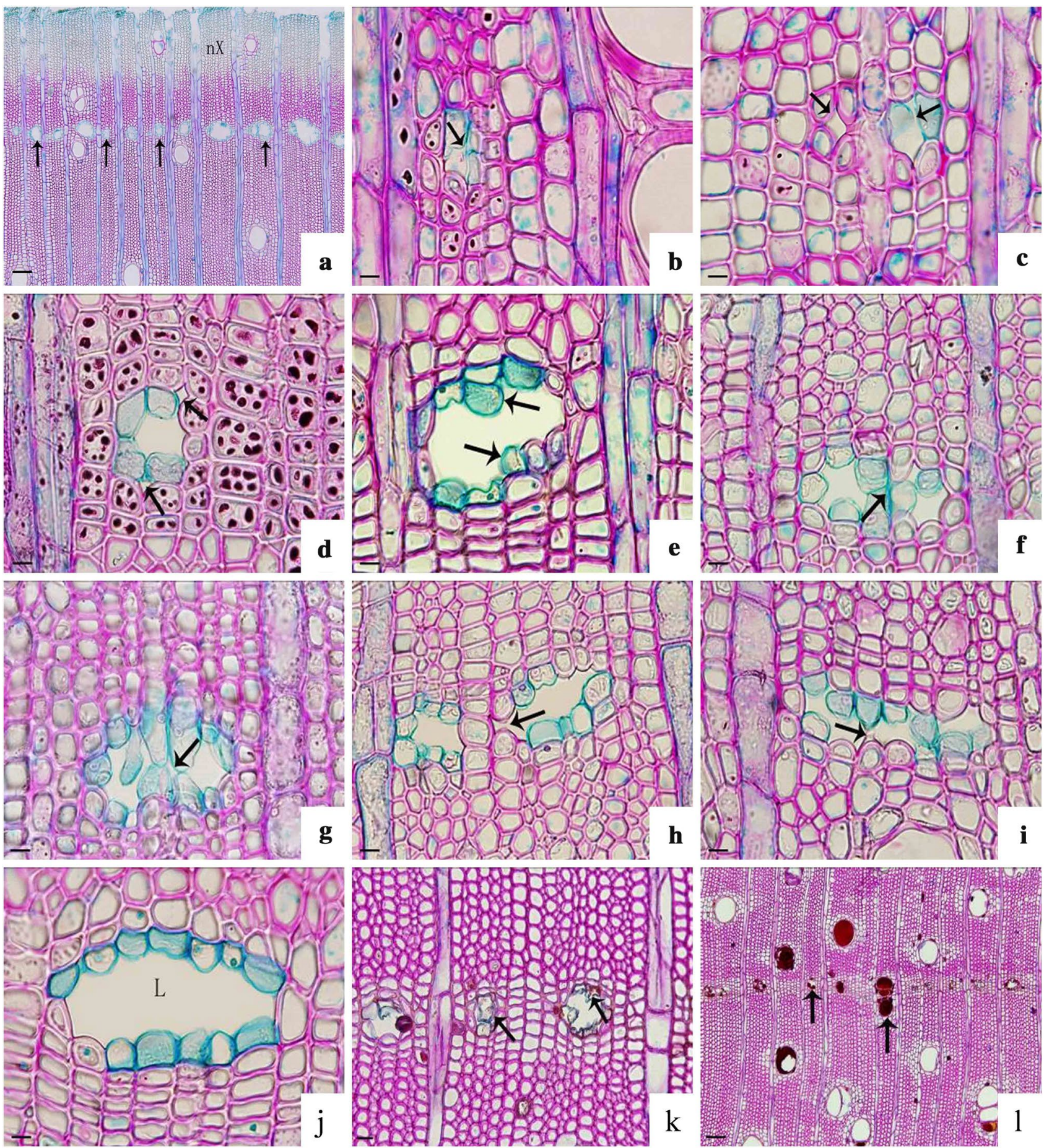

Fig. 5 The anatomy of intercellular canals in the outer sapwood and heartwood of $S$. glabra. a Secretary canals distributed along the marginal parenchyma bands (arrow); b cross section showing the initialjuxtaposed parenchyma cells (arrow); c secretory space gradually formed (arrow); $\mathbf{d}$ the newly formed secretory canals formed intercellular space (arrow); e the secretory lumen enlarged by the anticlinal and periclinal division of the living epithelial cells (arrow); $\mathbf{f}-\mathbf{i}$ the fusion between two adjacent axial canals resulted from the separation of juxtaposed radial cells (arrow); $\mathbf{j}$ fully differentiated canals; $\mathbf{k}$ the damaged wall of epithelial cells (arrow); $\mathbf{l}$ the vessels and epithelial cells filled with gum (arrow). $n X$ new xylem, $L$ lumen, $V S$ vessel, $r a$ xylem ray, $I C$ initial cell, $E p$ epithelial cell, $S h$ sheath cell. Scale bars, $\mathbf{a}, \mathbf{l}=100 \mu \mathrm{m} ; \mathbf{b}-\mathbf{j}=10 \mu \mathrm{m} ; \mathbf{k}=20 \mu \mathrm{m}$ 
Table 4 Geographical variation in secretory canal traits of $S$. glabra
Table 5 Variation of secretory canal traits among individuals with different $\mathrm{DBH}$

\begin{tabular}{llllllll}
\hline Population & SCTD & SCA & SCD & SCTA & SCF & SCTTD & MBF \\
\hline JFL & $61 \pm 0.7 \mathrm{a}$ & $1324 \pm 67 \mathrm{a}$ & $2.7 \pm 0.19 \mathrm{a}$ & $3806 \pm 414 \mathrm{a}$ & $5.6 \pm 0.11 \mathrm{~b}$ & $342 \pm 8 \mathrm{a}$ & $0.48 \pm 0.034 \mathrm{a}$ \\
DLS & $59 \pm 1.0 \mathrm{a}$ & $1212 \pm 43 \mathrm{a}$ & $2.1 \pm 0.11 \mathrm{~b}$ & $2509 \pm 140 \mathrm{~b}$ & $5.9 \pm 0.15 \mathrm{ab}$ & $345 \pm 9 \mathrm{a}$ & $0.36 \pm 0.022 \mathrm{~b}$ \\
BWL & $58 \pm 1.5 \mathrm{ab}$ & $1317 \pm 80 \mathrm{a}$ & $2.1 \pm 0.18 \mathrm{~b}$ & $2864 \pm 254 \mathrm{~b}$ & $5.5 \pm 0.12 \mathrm{~b}$ & $321 \pm 11 \mathrm{~b}$ & $0.36 \pm 0.012 \mathrm{~b}$ \\
WZS & $55 \pm 1.2 \mathrm{~b}$ & $1264 \pm 8 \mathrm{a}$ & $2.7 \pm 0.16 \mathrm{a}$ & $3247 \pm 216 \mathrm{ab}$ & $6.1 \pm 0.18 \mathrm{a}$ & $337 \pm 14 \mathrm{a}$ & $0.44 \pm 0.025 \mathrm{a}$ \\
\hline
\end{tabular}

Data are means \pm standard error. The different letters after values in the same row indicate significant differences $(p<0.05)$

\begin{tabular}{llllllll}
\hline DBH $(\mathrm{cm})$ & SCTD & SCA & SCD & SCTA & SCF & SCTTD & MBF \\
\hline $20-35$ & $56 \pm 1.0 \mathrm{~b}$ & $1271 \pm 67 \mathrm{ab}$ & $2.3 \pm 0.18 \mathrm{a}$ & $2908 \pm 276 \mathrm{a}$ & $6.0 \pm 0.16 \mathrm{a}$ & $339 \pm 12 \mathrm{ab}$ & $0.38 \pm 0.025 \mathrm{a}$ \\
$36-50$ & $57 \pm 0.9 \mathrm{~b}$ & $1211 \pm 63 \mathrm{~b}$ & $2.3 \pm 0.18 \mathrm{a}$ & $2784 \pm 213 \mathrm{a}$ & $5.7 \pm 0.13 \mathrm{a}$ & $322 \pm 8 \mathrm{~b}$ & $0.39 \pm 0.018 \mathrm{a}$ \\
$51-65$ & $58 \pm 0.9 \mathrm{~b}$ & $1258 \pm 68 \mathrm{ab}$ & $2.4 \pm 0.13 \mathrm{a}$ & $3035 \pm 271 \mathrm{a}$ & $5.6 \pm 0.11 \mathrm{a}$ & $325 \pm 8 \mathrm{~b}$ & $0.43 \pm 0.024 \mathrm{a}$ \\
$66-80$ & $64 \pm 1.0 \mathrm{a}$ & $1432 \pm 81 \mathrm{a}$ & $2.5 \pm 0.24 \mathrm{a}$ & $3615 \pm 418 \mathrm{a}$ & $5.7 \pm 0.16 \mathrm{a}$ & $365 \pm 11 \mathrm{a}$ & $0.44 \pm 0.044 \mathrm{a}$ \\
\hline
\end{tabular}

Data are means \pm standard error. The different letters after values in the same row indicate significant differences $(p<0.05)$

\begin{tabular}{llllllll}
\hline Age $(\mathrm{y})$ & SCTD & SCA & SCD & SCTA & SCF & SCTTD & MBF \\
\hline $40-100$ & $56 \pm 3.6 \mathrm{a}$ & $1220 \pm 261 \mathrm{a}$ & $2.3 \pm 0.54 \mathrm{a}$ & $2802 \pm 878 \mathrm{a}$ & $5.8 \pm 0.6 \mathrm{a}$ & $327 \pm 4 \mathrm{a}$ & $0.39 \pm 0.08 \mathrm{a}$ \\
$101-200$ & $62 \pm 4.2 \mathrm{~b}$ & $1402 \pm 306 \mathrm{a}$ & $2.9 \pm 0.76 \mathrm{~b}$ & $4038 \pm 141 \mathrm{~b}$ & $5.7 \pm 0.5 \mathrm{a}$ & $351 \pm 35 \mathrm{a}$ & $0.51 \pm 0.13 \mathrm{~b}$ \\
\hline
\end{tabular}

Data are means \pm standard error. The different letters after values in the same column indicate significant differences $(p<0.05)$

$Y$ year
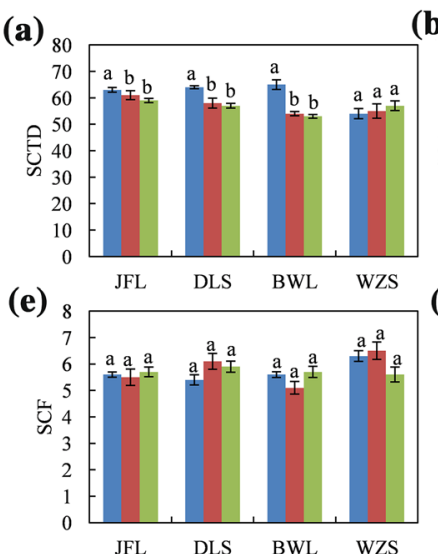

(b)
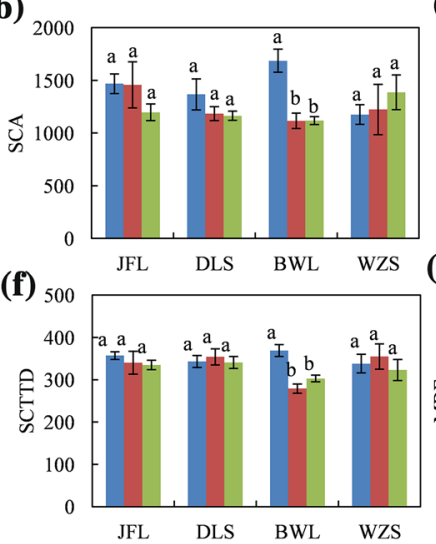

Fig. 6 Secretory canal traits among different oleoresin yield grades. a SCTD: tangential diameter of secretory canal; b SCA: area of secretory canal; c SCD: density of secretory canals; d SCTA: total area (c)

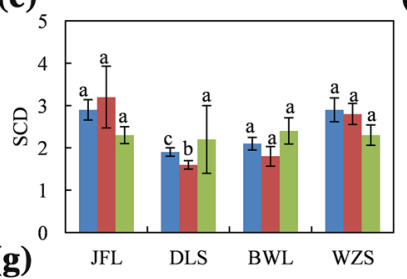

(g)

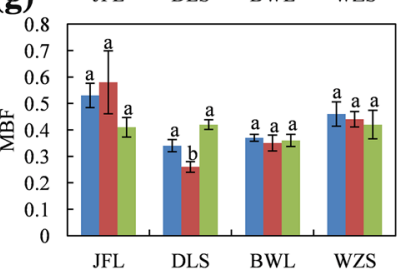

(d)

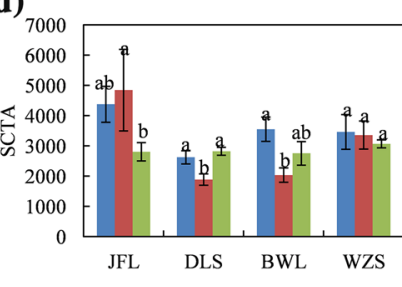

$$
\begin{array}{|l|}
\hline \square \mathrm{HY} \\
\square \mathrm{MY} \\
\square \mathrm{LY} \\
\hline
\end{array}
$$

of secretory canals; e SCF: frequency of secretory canals; f SCTTD: total tangential diameter of secretory canals; $\mathbf{g} \mathrm{MBF}$ : frequency of marginal bands. $H Y$ high yield, $M Y$ medium yield, $L Y$ low yield

$<0.01)$ were found between the area of secretory canals and the oleoresin yield from DLS and BWL areas.

The estimated plant age was positively correlated with the tangential diameter, density, total area and frequency (Table 7). In addition, significant positive correlations ( $p$ 
Table 7 Correlation analysis among secretory canal traits and oleoresin yield in populations

\begin{tabular}{lccrrrrr}
\hline Yield & SCTD & \multicolumn{1}{l}{ SCA } & \multicolumn{1}{l}{ SCD } & SCTA & \multicolumn{1}{l}{ SCF } & \multicolumn{1}{l}{ SCTTD } & \multicolumn{1}{c}{ MBF } \\
\hline JFL & $0.631^{*}$ & 0.367 & 0.323 & 0.407 & 0.033 & 0.368 & 0.311 \\
DLS & $0.5711^{*}$ & $0.720^{* *}$ & -0.305 & 0.197 & -0.189 & 0.178 & -0.224 \\
BWL & $0.802^{* *}$ & $0.577^{* *}$ & -0.095 & 0.410 & 0.038 & $0.678^{*}$ & -0.167 \\
WZS & -0.184 & -0.351 & 0.337 & 0.025 & 0.328 & 0.132 & 0.173 \\
\hline
\end{tabular}

**Highly significant differences $(p<0.01)$, *significant differences $(p<0.05)$ of marginal bands, whereas growth rate was negatively correlated with the four indicators (Table 8).

\section{Discussion}

In this study, the oleoresin yield and composition and stem structural features of $S$. glabra were investigated among populations from different localities. Although the four populations were all located in Hainan Island, the oleoresin amount and composition from different regions showed significant differences (Tables 2 and 3). The variation of secondary metabolites among populations was also reported in other species such as Copaifera langsdorffii (Martins et al. 2013) and Artemisia saharae (Zouari et al. 2014). Factors that determine the chemical yield of species include physiological, environmental, geographic and genetic variations (Figueiredo et al. 2008). In S. glabra, large-diameter trees produced higher amounts of oleoresin than small-diameter trees until tree DBH was over $80 \mathrm{~cm}$, indicating that the physiological stage of plants could affect the oleoresin production. Nevertheless, even at the same DBH class, individuals from DLS and BWL always produced higher oleoresin yield than those from JFL and WZS (Table 2), suggesting that geography exerted greater influence in determining oleoresin yield than DBH. Although the forest stand type of all four populations belongs to the same tropical lowland rainforest, ecological factors such as light intensity, water availability and soil type were different among populations. The main type of soil in BWL and JFL are laterite, while in DLS and WZS are yellow soil. These factors could affect the physiological and ecological responses of $S$. glabra individuals, which then lead to change in secondary metabolites. Furthermore, there was a high level of genetic diversity in $S$. glabra populations and the variation mainly occurred within populations (Yang et al. 2016). Therefore, genetic factors could also contribute to certain extent to the variation of oleoresin yield in S. glabra.

The effect of season on the oleoresin yield of S. glabra was further examined. In Hainan Island, the climate exhibits obvious seasonal contrasts between the dry season (from April to September) and rainy season (from October to March) (Fig. 3a). The average temperature in the wet season was higher than in the dry season. However, the relative humidity and solar irradiance did not show regular variation between the dry and wet seasons. Interestingly, our results showed that the oleoresin production in the wet season was also higher compared to the dry season (Fig. 3b). Rainfall and temperature could stimulate photosynthesis which provides more carbon and energy availability that are essential for the production of secondary metabolites (Gershenzon 1984). A seasonal effect on the production of secondary metabolites has been found in Liquidambar formosana (Chuang et al. 2018). Studies on Copaifera species have shown that Copaiba plants from semideciduous seasonal forests show differences in their phytochemical profile obtained in dry and wet seasons (Almeida et al. 2014), which are consistent with those in S. glabra.

GC-MS analysis revealed that the oleoresin of S. glabra was mainly composed of sesquiterpene $\alpha$-copaene and $\beta$-caryophyllene. The sesquiterpene compounds were qualitatively rather similar among individuals, suggesting that all individuals of $S$. glabra from four populations belong to the same chemotype. However, the amount of the four sesquiterpene compounds varied significantly between populations. Several factors including climate, geography, altitude, soil, and water could influence the composition of secondary metabolite. Drought stress altered the concentration of wood terpenoids in Scots pine and Norway spruce (Turtola et al. 2003). In S. glabra, we can conclude that geography,
Table 8 Correlation analysis among secretory canal traits and growth rate

\begin{tabular}{lrrrrrrr}
\hline & SCTD & SCA & SCD & SCTA & SCF & SCTTD & MBF \\
\hline Age $(\mathrm{y})$ & $0.575^{* *}$ & 0.191 & $0.483^{* *}$ & $0.474^{* *}$ & -0.206 & 0.231 & $0.573^{* *}$ \\
DBH $(\mathrm{cm})$ & $0.464^{* *}$ & 0.161 & 0.241 & 0.295 & -.370 & 0.022 & $0.419^{*}$ \\
Growth rate $(\mathrm{mm} / \mathrm{y})$ & $-0.455^{* *}$ & -0.180 & $-0.422^{*}$ & $-0.403^{*}$ & 0.044 & -0.282 & $-0.429^{*}$ \\
\hline
\end{tabular}

$Y$ year

**Highly significant differences $(p<0.01)$, *significant differences $(p<0.05)$ 
temperature, precipitation and tree diameter are the major factors affecting oleoresin yield and variation in chemical composition. Individuals with large diameter from DLS and BWL areas have high potential for exploitation and seeds from these trees should be collected for long-term breeding programs.

Normal secretory canals are seldom found in secondary xylem of broadleaf trees. Nevertheless, traumatic canals were formed in response to injury, which are arranged in tangential bands, generally irregular in outline and closely spaced (Wheeler et al. 1989; Bollschweiler et al. 2008). These traumatic secretory ducts can be found in broadleaf tree including Meliaceae (Dünisch and Baas 2006), Rosaceae, Elaeocarpaceae, and Proteaceae family, but mostly in conifer trees such as Cedrus (Fahn et al. 1979; Fahn 1979) and Abies (Fäldt et al. 2003). In Meliaceae species, the formation of the intercellular canals can be induced by wounding of the primary meristems and by wounding of the cambium. Moreover, in fast-growing trees of Carapa spp., Entandrophragma utile, and Khaya ivorensis, numerous canals were found which may be triggered by high growth stresses (Dünisch and Baas 2006). The secretory canals in secondary xylem of S. glabra are distributed in tangential direction, and they are arranged uniformly from the cambium to pith and exhibit regular shape and are also separated by xylem ray. Therefore, the secretory canals found in the stem of $S$. glabra are regular secretory canals instead of traumatic secretory canals. However, in the InsideWood database (https://insidewood.lib.ncsu.edu/ search), two Sindora species including Sindora supa Merr. and Sindora klaineana Pierre are reported to have both normal axial canals and intercellular canals of traumatic origin. Therefore, the borderline between these two types of canals may be rather gradual.

Several quantitative anatomical features such as the diameter, area, total area and total diameter of secretory canals were significantly different between populations of S. glabra. Ecological factors such as light and temperature and geographical distances were proposed to have strong effect on anatomic features of Copaifera langsdorffii and Boswellia papyrifera. In $S$. glabra, the variation of anatomical features was attributable to geography and tree diameter. Further study on the effect of ecological factors on stem anatomy should be conducted. The individuals with higher oleoresin yield from JFL, DLS and BWL areas showed larger diameter, area, total area and total diameter in secretory canals than those with lower oleoresin yield. This suggested that xylem with abundant secretory canals had higher ability to synthesize and secrete secondary metabolites, which was also reported in Pinaceae (Rodríguez-García et al. 2014). Therefore, the tangential diameter and area of secretory canals could be used as indicators for estimation of oleoresin yield. In summary, geography, tree diameter and tangential diameter and area of secretory canals could be useful for prediction of oleoresin yield. Furthermore, individuals from DLS and BWL areas produced higher amounts of oleoresin than those from JFL and WZS. Anatomical analysis also indicated that DLS and BWL were similar in their anatomical features. In addition, the growth rate was found to play negative roles in the formation of secretory canals. Dünisch and Baas (2006) reported that in fast growing trees of Carapa spp., Entandrophragma utile, and Khaya ivorensis, high growth stresses could be a further trigger for the traumatic formation of intercellular canals. Detailed studies on the anatomy at young stage of $S$. glabra are needed to further clarify the origin of secretory canals.

\section{Conclusions}

Geography and tree diameter were the major factors affecting oleoresin yield, and dry and wet seasons did also influence the oleoresin amount. Sesquiterpenes $\alpha$-copaene and $\beta$-caryophyllene were the major components of oleoresin in S. glabra stems and their amounts showed significant difference among populations. Structural analysis revealed that the tangential diameter, density of secretory canals and frequency of marginal bands increased with increasing stem diameter. Furthermore, the tangential diameter and area of secretory canals were positively correlated with oleoresin yield. This suggests that tree diameter and tangential diameter and area of secretory canals could be used as positive indicators for the estimation of oleoresin yield in S. glabra.

Acknowledgements This research was supported by National Natural Science Foundation of China (31570656) and Fundamental Research Funds of Chinese Academy of Forestry (CAFYBB2018QB003 and CAFYBB2017SY023).

Author contribution statement Conceptualization, NY and JY; methodology, QL; software, QL; validation, QL, GY and RL; formal analysis, WZ; investigation, GY; resources, JY; data curation, NY; writing—original draft preparation, NY; writing—review and editing, JY; visualization, GT; supervision, JY; project administration, GY.

\section{Compliance with ethical standards}

Conflict of interest The authors declare no conflict of interest.

Open Access This article is licensed under a Creative Commons Attribution 4.0 International License, which permits use, sharing, adaptation, distribution and reproduction in any medium or format, as long as you give appropriate credit to the original author(s) and the source, provide a link to the Creative Commons licence, and indicate if changes were made. The images or other third party material in this article are included in the article's Creative Commons licence, unless indicated otherwise in a credit line to the material. If material is not included in the article's Creative Commons licence and your intended use is not permitted by statutory regulation or exceeds the permitted use, you will 
need to obtain permission directly from the copyright holder. To view a copy of this licence, visit http://creativecommons.org/licenses/by/4.0/.

\section{References}

Almeida LFR, Portella RO, Facanali R, Marques MOM, Frei F (2014) Dry and wet seasons set the phytochemical profile of the Copaifera langsdorffii Desf. essential oils. J Essent Oil Res 26(4):292-300

Bollschweiler M, Stoffel M, Schneuwly D (2008) Traumatic resin ducts in Larix deciduas stems impacted by debris flows. Tree Physiol 28(2):255-263

Bolutari EB, Polonini HC, Zimmermam-Franco DC (2013) Antifungal activity of Copaifera langsdorffii desf oleoresin against dermatophytes. Molecules 18(10):12561-12570

Cascon V, Gilbert B (2000) Characterization of the chemical composition of oleoresins of Copaifera guianensis Desf., Copaifera dockei Dwyer and Copaifera multijuga Hayne. Photochemistry 55(7):773-778

Chuang L, Wen CH, Lee YR, Lin YL, Hsu LR, Wang SY, Chu FH (2018) Identification, functional characterization, and seasonal expression patterns of five sesquiterpene synthases in Liquidambar formosana. J Nat Prod 81(5):1162-1172

Dünisch O, Baas P (2006) On the origin of intercellular canals in the secondary xylem of selected Meliaceae species. IAWA J 27(3):281-297

Fahn A (1979) Secretory tissues in plants. Academic Press, London

Fahn AE, Werker P, Ben T (1979) Seasonal effects of wounding and growth substances on development of traumatic resin ducts in Cedrus libani. New Phytol 82(2):537-544

Fäldt J, Martin D, Miller B, Rawat S, Bohlmann J (2003) Traumatic resin defense in Norway spruce (Picea abies): methyl jasmonateinduced terpene synthase gene expression, and cDNA cloning and functional characterization of (+)-3-carene synthase. Plant Mol Biol 51(1):119-133

Figueiredo AC, Barroso JG, Pedro LG. Scheffer JJC (2008) Factors affecting secondary metabolite production in plants: volatile components and essential oils. Flavour Fragr J 23:213-226

Gershenzon J (1984) Changes in the Levels of Plant Secondary Metabolites Under Water and Nutrient Stress. In: Timmermann BN, Steelink C, Loewus FA (eds) Phytochemical Adaptations to Stress: Recent Advances in Phytochemistry. Springer, Boston, pp 273-320

Inside Wood (2004) Inside Wood, 2004-onwards. Published on the Internet. http://insidewood.lib.ncsu.edu/search. Accessed 16 Jan 2020

Langenheim JH (1990) Plant resins. Am Sci 78(1):16-24

Liang SJ, Wu H, Lun X, Lu DW (2006) Secretory cavity development and its relationship with the accumulation of essential oil in fruits of Citrus medica L.var.sarcodactylis (Noot.) Swingle. J Integr Plant Biol 48(5):573-583

Lombardero MJ, Ayres MP, Lorio JPL, Ruel JJ (2000) Environmental effects on constitutive and inducible resin defences of Pinus taeda. Ecol Lett 3(4):329-339
Mantuano DG, Barros CF, Scarano FR (2006) Leaf anatomy within and between three "restinga" populations of Erythroxylum ovalifolium Peyer. (Erythroxylaceae) in Southeast Brazil. Revista Brasil Bot 29:209-215

Martins K, Herrero C, Costa P, Tonini H, Bentes-Gama MD, Vieira A, Wadt LO (2013) Interspecific differences in the oleoresin production of Copaifera L. (Fabaceae) in the Amazon rainforest. Ann For Sci 70(3):319-328

Medeiros SR, Vieira G (2008) Sustainability of extraction and production of copaiba (Copaifera multijuga Hayne) oleoresin in Manaus, AM, Brazil. For Ecol Manag 256(3):282-288

Plowden C (2003) Production ecology of Copaiba (Copaifera spp.) oleoresin in the eastern Brazilian Amazon. Econ Bot 57(4):491-501

Rodrigues TM, Buarque P, Coneglian AG, Reis DC (2014) Light and temperature induce variations in the density and ultrastructure of the secretory spaces in the diesel-tree (Copaifera langsdorffii Desf.-Leguminosae). Trees 28(2):613-623

Rodríguez-García A, López R, Martín JA, Pinillos F, Gil L (2014) Resin yield in Pinus pinaster is related to tree dendrometry, stand density and tapping-induced systemic changes in xylem anatomy. For Ecol Manag 313:47-54

Rosner S, Hannrup B (2004) Resin canal traits relevant for constitutive resistance of Norway spruce against bark beetles: environmental and genetic variability. For Ecol Manag 200:77-87

Tolera M, Menger D, Sass-Klaassen U, Sterck FJ, Copini P, Bongers F (2013) Resin secretory structures of Boswellia papyrifera and implications for frankincense yield. Ann Bot 111(1):61-68

Trindade R, da Silva JK, Setzer WN (2018) Copaifera of the neotropics: a review of the phytochemistry and pharmacology. Int J Mol Sci 19(5):E1511

Turtola S, Manninen AN, Rikala R, Kainulainen P (2003) Drought stress alters the concentration of wood terpenoids in Scots pine and Norway spruce seedlings. J Chem Ecol 29:1981-1994

Wheeler EA, Baas P, Gasson PE (1989) IAWA list of microscopic features for hardwood identification: with an appendix on nonanatomical information. IAWA Bulletin 10(3):219-332

Yang JC, Li QQ, Yu N, Yin GT, Wu ZF, Li RS, Zou WT (2016) Genetic diversity and structure among natural populations of Sindora glabra in Hainan Island, China as revealed by ISSR markers. Biochem Syst Ecol 69:145-151

Zoghbi MGB, Lameira OA, Oliveira ECP (2007) Seasonal variation of oleoresin and volatiles from Copaifera martii Hayne growing wild in the state of Para. Brazil J Essent Oil Res 19(6):504-506

Zouari S, Ayadi I, Fakhfakh N, Jdir H, Aloui L, Kossentini M, Rebai A, Zouari N (2014) Essential oil variation in wild populations of Artemisia saharae (Asteraceae) from Tunisia: chemical composition, antibacterial and antioxidant properties. Bot Stud 55(1):76

Publisher's Note Springer Nature remains neutral with regard to jurisdictional claims in published maps and institutional affiliations. 